\title{
Visual search asymmetry: The influence of stimulus familiarity and low-level features
}

\author{
JIYE SHEN and EYAL M. REINGOLD \\ University of Toronto, Toronto, Ontario, Canada
}

\begin{abstract}
Wang, Cavanagh, and Green (1994) demonstrated a pop-out effect in searching for an unfamiliar target among familiar distractors (U-F search) and argued for the importance of a familiarity difference between the target and the distractors in determining search efficiency. In four experiments, we explored the generality of that finding. Experiment 1 compared search efficiency across a variety of targetdistractor pairs. In Experiments 2, 3, and 4, we used Chinese characters and their transforms as targets and distractors and compared search performance between Chinese and non-Chinese participants. We demonstrated that search asymmetry and search efficiency in the U-F condition are influenced by the presence of low-level feature differences between the familiar and the unfamiliar stimuli. Our findings suggest that the familiarity of the distractors, rather than the familiarity difference between the target and the distractors, determines search efficiency. We also documented a counterintuitive familiarityinferiority effect, suggesting that knowledge of search stimuli may, sometimes, be detrimental to search performance.
\end{abstract}

A substantial amount of research has focused on the influence of stimulus familiarity on visual processing (e.g., Christie \& Klein, 1996; Frith, 1974; Johnston \& Schwarting, 1996; Krueger, 1975, 1984; Kuehn \& Jolicœur, 1994; Lajoy \& Seethoff, 1974; Polk \& Farah, 1995; Reicher, Snyder, \& Richards, 1976; Reingold \& Jolicœur, 1993; Richards \& Reicher, 1978; Suzuki \& Cavanagh, 1995). One important finding reported in several studies is familiarity-based search asymmetry. Search asymmetry is defined as a change in search efficiency that occurs when the target and the distractor switch roles (Treisman \& Gormican, 1988; Treisman \& Souther, 1985). In the case of familiarity-based search asymmetry, an unfamiliar target (e.g., reflected, rotated letters or novel character sets) is detected more rapidly among familiar distractors (U-F condition), as compared with a familiar target among unfamiliar distractors ( $\mathrm{F}-\mathrm{U}$ condition). This pattern of findings has been reported in visual search with letters and digits (Frith, 1974; Reicher et al., 1976; Richards \& Reicher, 1978), faces (Kuehn \& Jolicœur, 1994), and three-dimensional shapes (Enns \& Rensink, 1991; Sun \& Perona, 1996; von Grünau \& Dubé, 1994). Despite research interest, the processes underlying search asymmetry are still not fully understood. In comparing search efficiency between the $\mathrm{U}-\mathrm{F}$ and $\mathrm{F}-\mathrm{U}$ conditions, the effects of target and distractor familiarity are confounded, because

Preparation of this manuscript was supported by a grant to E.M.R. from the Natural Science and Engineering Research Council of Canada (NSERC). We thank Jeremy Wolfe and reviewers for their helpful comments on an earlier version of this manuscript. Correspondence concerning this article should be addressed to either J. Shen or E. M. Reingold, Department of Psychology, University of Toronto, 100 St. George Street, Toronto, Ontario M5S 3G3, Canada (e-mail: jiye@psych.utoronto.caor reingold@psych.utoronto.ca). a familiar target is paired with unfamiliar distractors and an unfamiliar target is paired with familiar distractors. The superior performance in the U-F condition could result from the familiarity of the distractors, the novelty of the target, or the joint influence of the target novelty and distractor familiarity.

Several previous studies have reported that distractor familiarity substantially facilitated visual search, whereas target familiarity was found to play a minor role in determining search efficiency. For example, Krueger (1984) asked participants to search for upright or reversed (left-toright mirror image) letters or digits among a background of upright or reversed letters or digits. He found that searches with normally oriented familiar stimuli were more efficient than those with reversed unfamiliar ones. The finding of more efficient search in the U-F condition than in the F-U condition was attributed to the familiarity of the distractors, rather than to that of the target, because the distractors occupied most display positions. The novelty of the target hurt the search "even when it could have been ... used as a signal to respond immediately" (Krueger, 1984, p. 563). Reicher et al. (1976) also found that searching for a target was faster and more accurate among familiar distractors (letters or digits) than among unfamiliar distractors (inverted letters and digits, or Gibson figures). Treisman and Souther (1985) similarly stressed the importance of distractor familiarity in the interpretation of search asymmetry by arguing that efficient search in the U-F condition was due to the fast speed with which the familiar distractors could be rejected.

In contrast to the emphasis on the importance of distractor familiarity, Treisman and Gormican (1988) argued that search asymmetry as a function of stimulus familiarity could be accounted for by their prototype-deviation hypothesis. According to that hypothesis, the unfamiliar 
deviating stimuli (inverted, mutilated, or mirror-image letters) were distinguished from the standard, familiar stimuli by their normal labels plus an extra feature specifying the presence of the deviation. The deviating stimuli elicited more activity than did the standard ones. Consequently, the different slopes associated with $\mathrm{U}-\mathrm{F}$ and $\mathrm{F}-\mathrm{U}$ searches were attributed to the differences in the Weber fraction. That is, searching for a high-activity target among low-activity distractors (searching for an unfamiliar target among familiar distractors) is fast. Conversely, searching for a low-activity target among high-activity distractors (searching for a familiar target among unfamiliar distractors) is much slower. However, these authors did not empirically test this theory with familiar versus unfamiliar stimuli.

Recently, Wang, Cavanagh, and Green (1994) advanced an explanation similar to that of Treisman and Gormican (1988). In their study, they demonstrated a dramatic effect of search asymmetry. In the F-U condition, searching for a familiar target $\mathrm{N}$ (or $\mathrm{Z}$ ) in displays of unfamiliar Иs (or $5 \mathrm{~s}$ ) was very inefficient, with slopes of approximately $50 \mathrm{msec} /$ item. In marked contrast, searching for an unfamiliar target $\Lambda$ (or $\Sigma$ ) among familiar letter distractors $\mathrm{Ns}$ (or $Z \mathrm{~s}$ ) in the U-F condition was very efficient, with virtually flat slopes ( 1 or $2 \mathrm{msec}$ for each additional distractor). This kind of search with shallow slopes is typically referred to as a pop-out effect or parallel search (Treisman \& Souther, 1985). In addition, they also found that searching for a familiar target $\bar{\Xi}$ (or $\Xi$ ) among familiar distractors $己 s$ or $(\bar{s})$ in the F-F condition was inefficient, with search slopes averaging about $30 \mathrm{msec} /$ item. Searching for an unfamiliar target Щ (or ЦЛ) among unfamiliar distractors $\amalg$ s or ( was even more inefficient (over $70 \mathrm{msec} / \mathrm{item}$ ). Summarizing these findings, Wang et al. argued that "a difference of familiarity between the target and the distractors was necessary for the search to be parallel if there were no other primitive feature differences" (p. 499). They further claimed that, like other features assessed by Treisman and Gormican, "familiarity itself might be considered a primitive feature which can be processed preattentively" (Wang et al., 1994, p. 499).

Wang et al. (1994) contrasted their study with previous ones by focusing on two important methodological issues. First, they used homogeneous instead of heterogeneous distractors in the display. They argued that failure to obtain a pop-out effect in the U-F search in previous studies (Reicher et al., 1976; Richards \& Reicher, 1978) was due in part to the use of heterogeneous distractors. Employing displays with homogeneous distractors in their study resulted in greater distractor-distractor similarity, which in turn led to more efficient search (Duncan \& Humphreys, 1989). More important, Wang et al. tried to control feature differences between the targets and the distractors within each search condition. They pointed out that parallel letter search after extended practice, demonstrated by Schneider and Shiffrin (1977) and Shiffrin and
Schneider (1977), could be due to the uncontrolled lowlevel feature differences between the targets and the distractors. Accordingly, Wang et al. restricted "the variation of low-level features between target and distractors and varied only familiarity" (p. 496). This was accomplished by using targets and distractors that were mirror images of each other.

Although Wang et al. (1994) tried to control the lowlevel feature variations, they acknowledged that their control was not complete, because in searching for an $\mathrm{N}$ (or $Z$ ) among $\Lambda \mathrm{s}$ (or $\Sigma \mathrm{s}$ ) and vice versa, there was still "a low-level feature (the orientation of the oblique) that distinguishes target from distractors" (p. 496). However, they discounted the importance of this feature difference by arguing that it was present in both the $\mathrm{F}-\mathrm{U}$ and $\mathrm{U}-\mathrm{F}$ conditions and thus could not have caused the difference in search performance between them. In addition, these authors did not consider the potential influence of the differences in basic features and global patterns between the $\mathrm{F}-\mathrm{U} / \mathrm{U}-\mathrm{F}$ conditions and the $\mathrm{F}-\mathrm{F} / \mathrm{U}-\mathrm{U}$ conditions on search efficiency. Specifically, the target and distractors in the $\mathrm{U}-\mathrm{F}$ and $\mathrm{F}-\mathrm{U}$ conditions ( $\mathrm{N}$ vs. $\mathrm{U}$, and $\mathrm{Z}$ vs. $\Sigma$ ) could be discriminated by a single feature (the orientation of the oblique). In contrast, those in the F-F and $\mathrm{U}-\mathrm{U}$ conditions ( $コ$ vs. 己, and Ш vs. Ш) could not be discriminated by such a difference (but by a specific combination of the same lines, instead). The importance of low-level feature differences on visual search and texture discrimination performance has been reported in several previous studies (e.g., Beck \& Ambler, 1972; Cheal, Lyon, \& Hubbard, 1991; Singer \& Lappin, 1976). Therefore, it is still unclear whether the differences across search conditions reported by Wang et al. reflected a difference in processing those stimuli at the physical level (feature difference and/or global pattern) or at the higher level (stimulus familiarity). In order to investigate the effects of target and distractor familiarity on search efficiency, it is critical that comparisons be based on thorough control of feature differences across all the conditions of interest.

The finding of familiarity-based search asymmetry and superior performance in detecting a novel target among familiar distractors reported by Wang et al. (1994) has potential implications for studies of visual processing and attentional mechanisms, such as the binding problem, perceptual learning, and stimulus representation (Desimone \& Duncan, 1995; Ellison \& Walsh, 1998; Goldstone, 1998; Wolfe, 1998; Wolfe \& Bennett, 1997). Given the theoretical importance of the finding by Wang et al., we planned to further examine this effect. In Experiments 1,2 , and 3 , we examined the generality of search asymmetry and the influence of a low-level feature difference on the efficient search performance in the U-F condition. In Experiment 4, we examined the effects of target and distractor familiarity on search performance with targetdistractor pairs that were matched in terms of both lowlevel features and emergent features (patterns created by a combination of features; e.g., Pomerantz, 1981). 


\section{EXPERIMENTS 1A AND 1B}

In the present experiments, we wanted to explore the generality of the familiarity-based search asymmetry and to further investigate whether or not a low-level feature difference, such as the orientation of the oblique, contributes to efficient search in the U-F condition. In Experiment 1A, we provided a replication of Wang et al. (1994) by using pairs of targets and distractors that differed in the orientation of the diagonal line. In Experiment 1B, we used target-distractor pairs that differed in the arrangement of lines, but not in their orientation.

\section{Method}

Participants. Sixteen undergraduate students (8 in Experiment $1 \mathrm{~A}$ and 8 in Experiment $1 \mathrm{~B}$ ) participated in a single 1-h session. All the participants had normal or corrected-to-normal vision, and their native language was English. They were paid $\$ 10$ or were given a course credit for their participation.

Stimuli and Design. Six pairs of stimuli, which were mirror images of each other, were used across two experiments. Either stimulus in each pair could be the search target, making the other a distractor, and vice versa. For the participants in Experiment 1A, the target-distractor pairs were $N$ versus $U$ and 4 versus $A$. For both pairs of stimuli, the target and the distractor differed in the orientation of the oblique. In Experiment 1B, the target-distractor pairs were $\zeta$ versus $H$, $G$ versus $\bar{D}, F$ versus $\exists$, and $L$ versus $\rfloor$, which differed in the arrangement of lines, but not in their orientation. The computer-generated stimuli subtended $0.6^{\circ}$ horizontally and $0.9^{\circ}$ vertically. In each display, the target could be either present or absent, and the number of items presented (display size) could be 2, 4, or 6 . All the items in the display appeared randomly at nine possible positions, which were evenly spaced on an imaginary $5.5^{\circ}$-diameter circle.

In both experiments, a four-factor within-subjects design was used. The factors were as follows: target-distractor pair ( $N$ vs. $M$ or 4 vs. $A$ in Experiment $1 \mathrm{~A}$ and 4 vs. $H$, $\bar{a}$ vs. $\bar{\theta}, F$ vs. $\exists$, or $L$ vs. $\downarrow$ in Experiment 1B), target presence (absent or present), search condition (U-F or F-U condition), and display size (2, 4, or 6). The participants in Experiment 1A searched two blocks of 90 trials for each of the four targets. Experiment 1B consisted of eight blocks of 108 trials, with one block for each target. In both experiments, the order of the search targets was counterbalanced across participants.

Procedure. The participants were seated $60 \mathrm{~cm}$ from the computer screen. At the beginning of each block, the search target was displayed on the screen, the participants pressed a key, and a fixation cross appeared at the center of the screen. A second keypress initiated the block with a sharp beep, and a display appeared $500 \mathrm{msec}$ later. The display remained on the screen until a response was made. The participants were asked to decide whether the target was present or absent by pressing an appropriate key as quickly and as accurately as possible. After an interval of $1,200 \mathrm{msec}$, another trial was initiated.

\section{Results and Discussion}

Error rates were generally low, averaging $4.7 \%$ in Experiment $1 \mathrm{~A}$ and $2.8 \%$ in Experiment 1B. There was no evidence of a speed-accuracy tradeoff. For each participant, an outlier analysis was performed within each cell of the design to eliminate those response times (RTs) that were more than 2.5 standard deviations above or below the mean. This resulted in the exclusion of $2.6 \%$ of the trials in Experiment $1 \mathrm{~A}$ and $1.9 \%$ of the trials in Experiment $1 \mathrm{~B}$ from further analysis. Figure 1 plots the RT as a function of target presence, search condition, and dis- play size for each target-distractor pair used. For each participant, slopes for target-present trials and target-absent trials were derived separately in each search condition by linear regression of RT on display size. ${ }^{1}$ Table 1 presents the search slopes and error rates averaged across participants.

Experiment 1A. Search slopes were analyzed with a repeated measures analysis of variance (ANOVA), with target-distractor pair, target presence, and search condition as within-subjects factors. Search slopes were steeper in target-absent trials than in target-present trials $[F(1,7)=$ $8.33, p<.05]$. Strong search asymmetry between the U-F and the $\mathrm{F}-\mathrm{U}$ conditions was observed $[F(1,7)=162.88$, $p<.001$ ], replicating the findings by Wang et al. (1994). Searching for $И$ among $N$ s was very efficient $(5.5 \mathrm{msec} /$ item), whereas searching for $\mathrm{N}$ among $\mathrm{hs}$ was extremely difficult ( $88.5 \mathrm{msec} /$ item $)$. Similarly, the unfamiliar target $A$ popped out of familiar distractors $(-4.2 \mathrm{msec} / \mathrm{item})$, whereas a steep search slope (39.9 msec/item) was observed when 4 was the target. In addition, search asymmetry for the $V$ versus $U$ pair was more pronounced than that for the 4 versus $A$ pair. This is shown in the significant target-distractor pair $\times$ search condition interaction $[F(1,7)=9.78, p<.05]$.

Experiment 1B. Search slopes were subjected to a 4 (target-distractor pair) $\times 2$ (target presence) $\times 2$ (search condition) repeated measures ANOVA. Search slopes were much shallower in target-present trials than in targetabsent trials $[F(1,7)=20.86, p<.001]$; this difference was observed in all pairs of stimuli except for the $L$ versus $\rfloor$ pair, as is indicated by a significant interaction between target presence and target-distractor pair $[F(3,21)=$ $3.11, p<.05]$. Again, the familiarity-based search asymmetry was found $[F(1,7)=53.58, p<.001]$. The strength of this effect differed across pairs of stimuli. Robust asymmetries were found for the $\sqcup$ versus $H$ pair (with a 36.6msec/item difference in search slope between the U-F and the $\mathrm{F}-\mathrm{U}$ conditions), the $\overline{5}$ versus $\mathrm{a}$ pair $(19.0$-msec/item difference), and the $L$ versus $\rfloor$ pair $(15.0$-msec/item difference; all $F \mathrm{~s}>6.48, p \mathrm{~s}<.05$ ). However, the difference between the $\mathrm{U}-\mathrm{F}$ and the $\mathrm{F}-\mathrm{U}$ search conditions was only marginally significant for the $\mathrm{F}$ versus 7 pair $[12.1-\mathrm{msec} /$ item difference; $F(1,7)=4.87, p=.063]$.

Table 1 reveals a wide range of search slopes for targetpresent trials in the U-F condition: $-2.4 \mathrm{msec} /$ item for 7 among Fs, $6.1 \mathrm{msec} /$ item for $\rfloor$ among $L \mathrm{~s}, 15.5 \mathrm{msec} /$ item for $\exists$ among $E_{s}$, and $18.4 \mathrm{msec} /$ item for $\boldsymbol{H}$ among $4 \mathrm{~s}$. Similarly, searches in the F-U condition also varied in efficiency among different target-distractor pairs. Searching for $F$ was very efficient $(9.8 \mathrm{msec} /$ item $)$, searching for $L$ was less efficient (19.1 msec/item), whereas searching for 4 and 5 was substantially less efficient (50.0 and $38.2 \mathrm{msec} /$ item, respectively).

Two conclusions can be drawn. First, search asymmetry is a continuous phenomenon in the sense that it can be very dramatic for some pairs of stimuli but only marginal for others. Second, the search efficiency in both the $\mathrm{U}-\mathrm{F}$ and the $\mathrm{F}-\mathrm{U}$ conditions also varies along a continuum, ranging from flat slopes to very steep search slopes. 

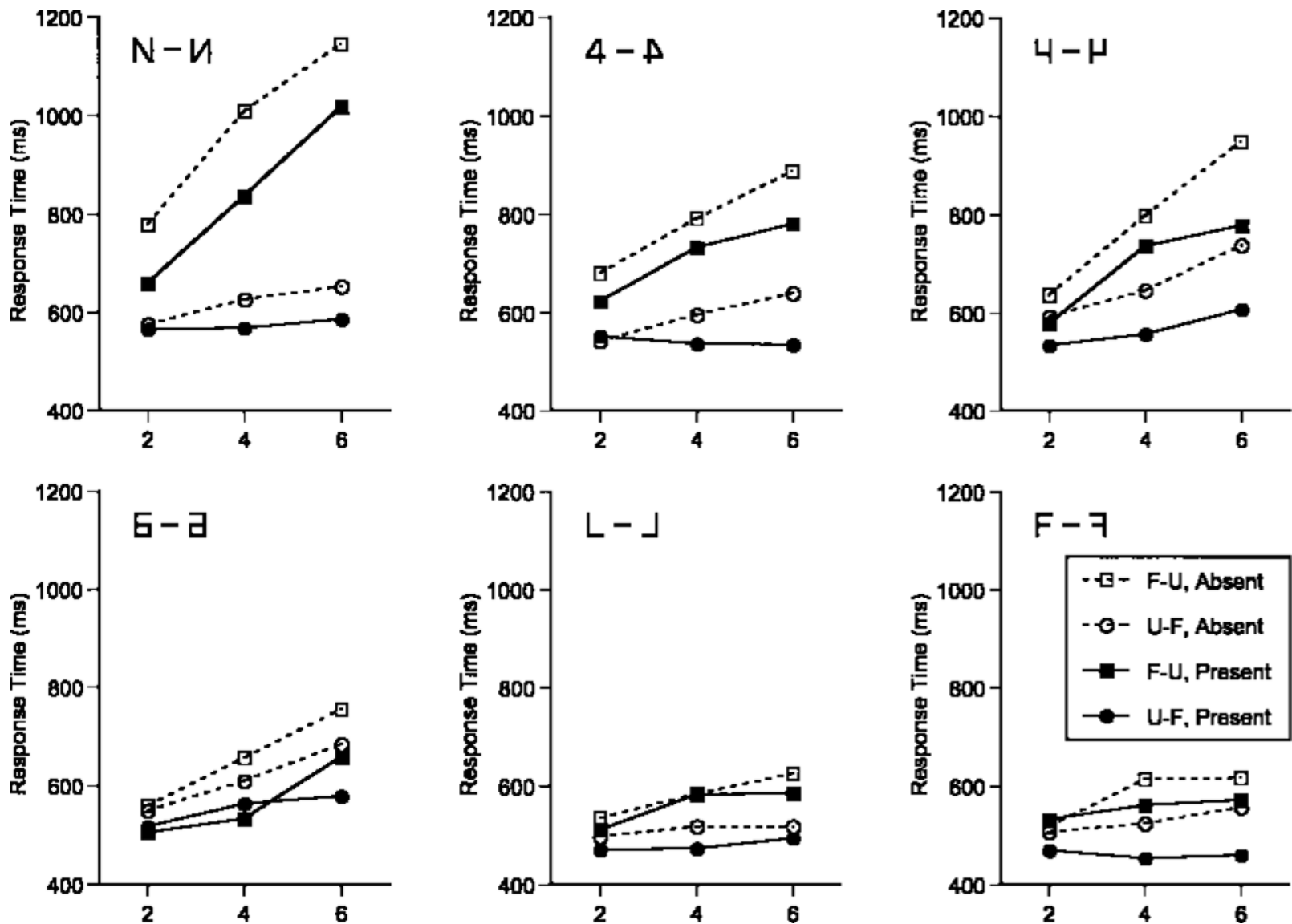

Figure 1. Response times as a function of target presence and display size for the target-distractor pairs used in Experiments $1 \mathrm{~A}$ and 1B. F-U, familiar target among unfamiliar distractors; U-F, unfamiliar target among familiar distractors.

Even within a single target-distractor pair, there were also large variations across participants (see Wolfe, 1998). The present Experiment $1 \mathrm{~A}$ replicated the very efficient U-F searches reported by Wang et al. (1994), under conditions in which the targets and the distractors differed in feature orientation. In contrast, in Experiment 1B, under conditions in which the targets and the distractors differed in line arrangement, but not in orientation, search was more variable, ranging from very inefficient in some target-distractor pairs to very efficient in others. Overall, we found that the search asymmetry appeared to be larger when targets and distractors differed in low-level features

Table 1

Search Slopes (in Milliseconds/Item) and Error Rates (ERs, in \%) in Experiments 1A and $1 B$

\begin{tabular}{|c|c|c|c|c|c|c|c|c|}
\hline \multirow[b]{3}{*}{ Experiment } & \multirow{3}{*}{$\begin{array}{c}\text { Target- } \\
\text { Distractor } \\
\text { Pair }\end{array}$} & \multirow{3}{*}{$\begin{array}{l}\text { Search } \\
\text { Condition }\end{array}$} & \multicolumn{3}{|c|}{ Target Present } & \multicolumn{3}{|c|}{ Target Absent } \\
\hline & & & \multicolumn{2}{|c|}{ Search Slope } & \multirow[b]{2}{*}{ ER } & \multicolumn{2}{|c|}{ Search Slope } & \multirow[b]{2}{*}{ ER } \\
\hline & & & $M$ & $S E$ & & $M$ & $S E$ & \\
\hline \multirow[t]{4}{*}{$1 \mathrm{~A}$} & $N_{\text {vs. }}$ M & $\mathrm{F}-\mathrm{U}$ & 88.5 & 10.2 & 8.5 & 91.3 & 11.8 & $\overline{6.4}$ \\
\hline & & U-F & 5.5 & 2.9 & 4.6 & 19.6 & 5.7 & 3.6 \\
\hline & 4 vs. $A$ & $\mathrm{~F}-\mathrm{U}$ & 39.9 & 8.5 & 5.3 & 51.8 & 8.8 & 3.6 \\
\hline & & $\mathrm{U}-\mathrm{F}$ & -4.2 & 2.7 & 3.1 & 24.5 & 5.7 & 2.7 \\
\hline \multirow[t]{8}{*}{$1 \mathrm{~B}$} & 4 vs. $\mapsto$ & $\mathrm{F}-\mathrm{U}$ & 50.0 & 6.6 & 3.8 & 78.1 & 11.2 & 3.0 \\
\hline & & $\mathrm{U}-\mathrm{F}$ & 18.4 & 6.3 & 3.1 & 36.5 & 7.1 & 2.7 \\
\hline & 巨 vs. 日 & $\mathrm{F}-\mathrm{U}$ & 38.2 & 4.6 & 4.4 & 49.1 & 10.2 & 2.5 \\
\hline & & U-F & 15.6 & 6.2 & 3.1 & 33.7 & 3.3 & 1.4 \\
\hline & L vs. 」 & $\mathrm{F}-\mathrm{U}$ & 19.1 & 7.9 & 2.5 & 22.5 & 6.6 & 1.4 \\
\hline & & U-F & 6.1 & 3.3 & 2.5 & 5.6 & 1.3 & 3.0 \\
\hline & $F_{\text {vs. }} \exists$ & $\mathrm{F}-\mathrm{U}$ & 9.8 & 4.6 & 4.4 & 24.5 & 5.3 & 1.9 \\
\hline & & $\mathrm{U}-\mathrm{F}$ & -2.4 & 2.4 & 2.8 & 12.6 & 7.0 & 2.7 \\
\hline
\end{tabular}

Note-F-U, familiar target among unfamiliar distractors; U-F, unfamiliar target among familiar distractors. 
(56.5 msec/item across target-distractor pairs in Experiment 1A), as compared with conditions in which the target-distractor pairs matched in terms of the low-level features [20.7 msec/item across target-distractor pairs in Experiment $1 \mathrm{~B} ; t(14)=6.82, p<.001]$. Thus, it seems that, in addition to stimulus familiarity, a difference in low-level features may have also partially mediated the search asymmetry and the pop-out effect reported by Wang et al.

The present experiments did not fully address several issues. The different target-distractor pairs we used may have varied in terms of stimulus familiarity. Consider the 4 versus $A$ pair in Experiment $1 \mathrm{~A}$ and the 4 versus $H$ pair in Experiment 1B, for example. It is possible that 4 may not be as familiar as 4 , resulting in a pop-out effect in the U-F condition in the latter, but not in the former. Note, however, that this concern may also be applicable to the stimulus set used by Wang et al. (1994). The F-F search condition in their study used $己$ and 5 , which may be less familiar than $\mathrm{N}$ and $\mathrm{Z}$ used in the $\mathrm{U}-\mathrm{F} / \mathrm{F}-\mathrm{U}$ conditions. An additional concern for interpreting the present findings is related to some of the stimulus pairs used in Experiment 1B. Although we have tried to control the lowlevel feature differences by using target-distractor pairs that differed in the arrangement of lines, but not in their orientation, a strong global orientation cue (i.e., facing left or facing right) may have been introduced in the $F$ versus $\exists$ and $L$ versus $J$ pairs. The presence of such a cue may have overridden the effect of stimulus familiarity, because it makes the shapes highly discriminable (i.e., yielding a floor effect). Consequently, a very weak search asymmetry and shallow search slopes in both the U-F and the F-U conditions were found in these target-distractor pairs.

\section{EXPERIMENT 2}

Experiments 2 and 3 were designed to further examine the robustness of search asymmetry and the possibility that the search asymmetry and efficient visual search in the U-F condition is partly mediated by a low-level feature difference. In both experiments, a Chinese character and an unfamiliar symbol were used. In Experiment 2, the target and the distractor differed only in the rearrangement of their components (古 vs. 古), whereas a difference in the orientation of the oblique in the target-distractor pair was present in Experiment 3 (舌 vs. 舌). To establish that the observed results represent the effects of stimulus familiarity, rather than uncontrolled feature differences, we adopted a cross-cultural approach in both experiments by comparing search performance between a group of participants who were familiar with the stimuli (the Chinese group) and another group of participants who were unfamiliar with the stimuli (the English group).

\section{Method}

Participants. Twelve Chinese speakers, who had over 12 years of experience in reading and writing Chinese, and 12 native English speakers, who had no knowledge of the Chinese language, were recruited from the University of Toronto and the local community.
All the participants had normal or corrected-to-normal vision. They participated in a single 1-h session and were paid $\$ 10$ for their participation.

Stimuli and Design. The search target and distractor used in the present experiment were a familiar Chinese character 古 (meaning old or ancient), with a character frequency of 290.0 per million (Beijing Institute of Language Teaching and Research, 1986), and its $180^{\circ}$ rotated form 古, which was unfamiliar to the Chinese readers. Both stimuli had the same components (a rectangle and a plus sign) and differed only in the relative positions of these two components. In the F-U search condition, 古 (familiar) was the search target and 무 (unfamiliar) was the distractor, whereas in the U-F condition, the target-distractor roles were switched. The individual target and distractor items subtended $0.9^{\circ}$ horizontally and $0.9^{\circ}$ vertically. In each display, the target and distractors could appear in seven possible positions, which were evenly spaced on an imaginary $5.5^{\circ}$-diameter circle.

A mixed design was adopted in the present experiment, with group (Chinese vs. English) being the between-subjects factor and target presence (absent or present), search condition (U-F or F-U), and display size $(2,4$, or 6$)$ being the within-subjects factors. Ten blocks of 60 trials were used, with five blocks in each search condition (U-F or F-U condition). The order of the search conditions was counterbalanced across participants. The experimental procedure was the same as that in Experiment 1.

\section{Results and Discussion}

Trials with incorrect response or with excessively long or short RTs were excluded from further analysis. These exclusions accounted for $3.8 \%$ and $2.3 \%$ for the Chinese group and $2.3 \%$ and $2.7 \%$ for the English group, respectively. For each participant, search slopes in both the U-F and the $\mathrm{F}-\mathrm{U}$ conditions were produced by relating $\mathrm{RT}$ to display size. The mean RTs are plotted in Figure 2, and the search slopes and error rates are shown in Table 2.

Search slopes were subjected to a repeated measures ANOVA, with target presence and search condition as within-subjects factors and group as the between-subjects factor. Overall, the Chinese group yielded much steeper search slopes ( $49.6 \mathrm{msec} / \mathrm{item})$ than did the English group [27.8 msec/item; $F(1,22)=8.26, p<.001]$. Search slopes were steeper in the target-absent trials $(44.0 \mathrm{msec} /$ item $)$ than in the target-present trials $[33.5 \mathrm{msec} / \mathrm{item} ; F(1,22)=$ $6.98, p<.05]$. More important, search asymmetry was observed for the Chinese group, with shallower slopes in the U-F condition ( $37.5 \mathrm{msec} /$ item) than in the F-U condition $(61.8 \mathrm{msec} /$ item $)$. In contrast, the search slopes for the English group did not differ between search conditions ( $26.9 \mathrm{msec} /$ item in the F-U condition and $28.7 \mathrm{msec} /$ item in the U-F condition). This difference in search performance between the two groups of participants is shown in the significant group $\times$ search condition interaction $[F(1,22)=7.17, p<.05]$.

Error rates also differed between the two groups. A repeated measures ANOVA, with target presence, search condition, and display size as within-subjects factors and group as the between-subjects factor, revealed that the Chinese group made slightly more errors than did the English group [3.8\% vs. $2.3 \% ; F(1,22)=3.63, p=.07]$. There was a significant triple interaction of group, search condition, and display size $[F(2,44)=3.40, p<.05]$. For the Chinese group, as the display size increased, search- 

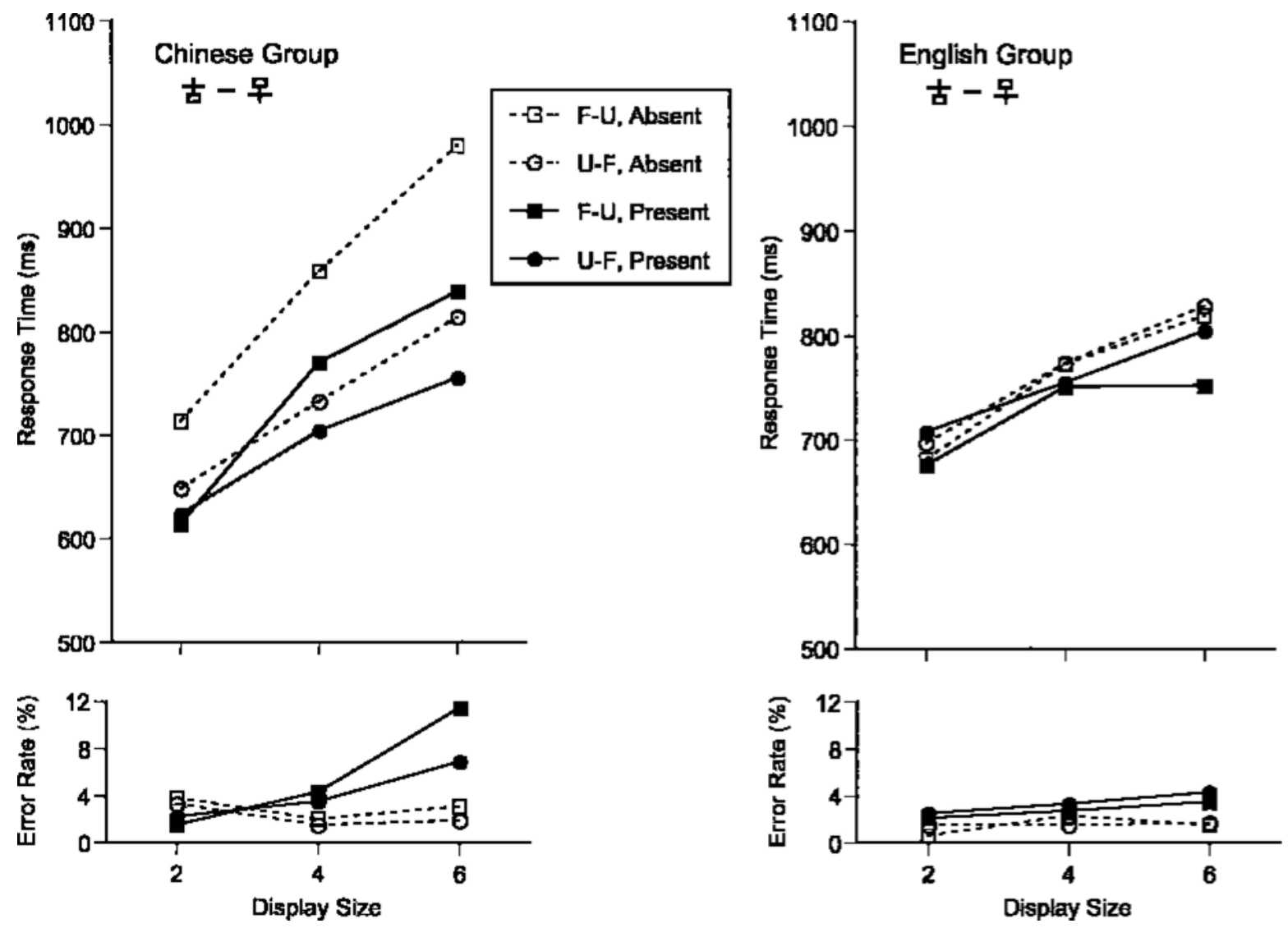

Figure 2. Response times and error rates as a function of target presence, search condition, and display size for the Chinese group and the English group in Experiment 2. F-U, familiar target among unfamiliar distractors; U-F, unfamiliar target among familiar distractors.

ing for the familiar target among unfamiliar distractors became more error prone than searching for the unfamiliar target among familiar distractors, as is indicated by a significant search condition $\times$ display size interaction $[F(2,22)=4.73, p<.05]$. This finding provides further evidence for the asymmetry in search performance between the U-F and the F-U conditions for the Chinese participants. As was expected, there was no such interaction for the English group $(F<1)$.

The present experiment made a cross-cultural comparison of visual search performance between the Chinese

Table 2

Search Slopes (in Milliseconds/Item) and Error Rates (ERs, in \%) for the Chinese Group and the English Group in Experiment 2

\begin{tabular}{|c|c|c|c|c|c|c|c|}
\hline \multirow[b]{3}{*}{ Group } & \multirow{3}{*}{$\begin{array}{c}\text { Search } \\
\text { Condition }\end{array}$} & \multicolumn{3}{|c|}{ Target Present } & \multicolumn{3}{|c|}{ Target Absent } \\
\hline & & \multicolumn{2}{|c|}{ Search Slope } & \multirow[b]{2}{*}{ ER } & \multicolumn{2}{|c|}{ Search Slope } & \multirow[b]{2}{*}{ ER } \\
\hline & & $M$ & $S E$ & & $M$ & $S E$ & \\
\hline \multirow[t]{2}{*}{ Chinese } & $\mathrm{F}-\mathrm{U}$ & 57.0 & 6.9 & 5.8 & 66.5 & 7.4 & 3.0 \\
\hline & U-F & 33.2 & 4.6 & 4.2 & 41.7 & 6.0 & 2.2 \\
\hline \multirow[t]{2}{*}{ English } & $\mathrm{F}-\mathrm{U}$ & 19.3 & 6.0 & 2.8 & 34.6 & 9.2 & 1.5 \\
\hline & U-F & 24.4 & 6.0 & 3.4 & 33.1 & 9.7 & 1.6 \\
\hline
\end{tabular}

Note-F-U, familiar target among unfamiliar distractors; U-F, unfamiliar target among familiar distractors. group, who had experience with the familiar item we used, and the English group, who were unfamiliar with the stimuli. We demonstrated a search asymmetry between the $\mathrm{F}-\mathrm{U}$ and the U-F conditions, with the latter being more efficient than the former in the Chinese group, but not in the English group. This difference in search performance between the two groups of participants suggests that the search asymmetry observed in the Chinese group is familiarity based. However, in the absence of a salient lowlevel feature difference, the Chinese group yielded steep search slopes in the U-F condition $(33.2 \mathrm{msec} / \mathrm{item}$ in target-present trials and $41.7 \mathrm{msec} /$ item in target-absent trials). A further inspection of the individual participants' search slopes in the U-F condition revealed that only one had a slope below $8 \mathrm{msec} /$ item, which qualified it as a popout search by the criterion adopted by Wang et al. (1994).

\section{EXPERIMENT 3}

To further examine the influence of a low-level feature difference on search asymmetry and search efficiency in the U-F condition, we adopted another pair of stimuli that differed in the orientation of the oblique. The search target and distractor used in the present experiment were a familiar Chinese character 舌 (meaning tongue), with 
a character frequency of 44.2 per million (Beijing Institute of Language Teaching and Research, 1986), and its mirror image form 舌, which was unfamiliar to the Chinese readers. In the F-U search condition, 舌 (familiar) was the search target and 舌 (unfamiliar) was the distractor, whereas in the U-F condition, the target and the distractor switched roles. Note that the frequency of the familiar character was chosen to be lower than the one used in Experiment 2. Consequently, a stronger search asymmetry than that in Experiment 2 and a more efficient search in the U-F condition, if observed in the present ex periment, would provide convincing evidence for the role of low-level feature difference.

\section{Method}

Another group of 8 native Chinese speakers and 8 native English speakers participated in a single 1-h session. The display configuration, experimental design, and procedure were the same as those in Experiment 2.

\section{Results and Discussion}

Trials with wrong response $3.9 \%$ of the trials in the Chinese group and $3.7 \%$ in the English group) or with extremely long or short RTs (1.8\% of the trials in the Chinese group and $2.9 \%$ in the English group) were eliminated from further analysis. The search slopes and error rates for both the Chinese group and the English group are presented in Table 3. Figure 3 plots RT and error rate as a function of target presence, search condition, and display size.

Search slopes were analyzed with a repeated measures ANOVA, with target presence (absent vs. present) and search condition (U-F vs. F-U) as within-subjects factors and group (Chinese vs. English) as the between-subjects factor. The overall search slope for the Chinese group (41.6 msec/item) was much steeper than that for the English group $(16.2 \mathrm{msec} / \mathrm{item} ; F(1,14)=8.13, p<.05]$. Figure 3 and Table 3 reveal that there was a strong search asymmetry for the Chinese group. Searches in the F-U condition were very inefficient $(56.2 \mathrm{msec} /$ item in the target-present trials and $73.0 \mathrm{msec} /$ item in the targetabsent trials). In marked contrast, shallower search slopes were observed in the U-F condition $(13.2 \mathrm{msec} / \mathrm{item}$ in the target-present trials and $24.2 \mathrm{msec} /$ item in the targetabsent trials). For the English group, search slopes did not

Table 3

Search Slopes (in Milliseconds/Item) and

Error Rates (ERs, in \%) for the Chinese Group and the English Group in Experiment 3

\begin{tabular}{|c|c|c|c|c|c|c|c|}
\hline \multirow[b]{3}{*}{ Group } & \multirow{3}{*}{$\begin{array}{c}\text { Search } \\
\text { Condition } \\
\end{array}$} & \multicolumn{3}{|c|}{ Target Present } & \multicolumn{3}{|c|}{ Target Absent } \\
\hline & & \multicolumn{2}{|c|}{$\underline{\text { Search Slope }}$} & \multirow[b]{2}{*}{ ER } & \multicolumn{2}{|c|}{$\underline{\text { Search Slope }}$} & \multirow[b]{2}{*}{ ER } \\
\hline & & $M$ & $S E$ & & $M$ & $S E$ & \\
\hline \multirow[t]{2}{*}{ Chinese } & $\mathrm{F}-\mathrm{U}$ & 56.2 & 7.6 & 8.1 & 73.0 & 16.2 & 2.4 \\
\hline & U-F & 13.2 & 4.5 & 3.4 & 24.2 & 8.4 & 1.9 \\
\hline \multirow[t]{2}{*}{ English } & $\mathrm{F}-\mathrm{U}$ & 10.8 & 3.2 & 4.9 & 22.0 & 10.2 & 2.4 \\
\hline & U-F & 14.7 & 4.1 & 5.0 & 17.4 & 5.6 & 2.8 \\
\hline
\end{tabular}

Note-F-U, familiar target among unfamiliar distractors; U-F, unfamiliar target among familiar distractors. differ between the $\mathrm{F}-\mathrm{U}$ condition $(10.8 \mathrm{msec} /$ item in the target-present trials and $22.0 \mathrm{msec} /$ item in the targetabsent trials) and the U-F condition (14.7 msec/item in target-present trials and $17.3 \mathrm{msec} /$ item in target-absent trials). This difference in search performance between the two groups of participants is confirmed by a significant group $\times$ search condition interaction $[F(1,14)=14.31$, $p<.001]$.

The Chinese group and the English group did not differ in the overall error rate $(3.9 \%$ vs. $3.7 \% ; \mathrm{F}<1)$. However, there was a significant four-way interaction: group $\times$ target presence $\times$ search condition $\times$ display size $[F(2,28)=3.79, p<.05]$. For the Chinese group, in the target-present trials, the participants made more errors with an increase in display size; this effect was more pronounced when the search target was familiar than when it was unfamiliar. In the target-absent trials, error rate was not influenced by display size or search condition. For the English group, the participants tended to make more errors with an increase in display size in the targetpresent trials, but not in the target-absent trials. As was expected, error rates for the English group were not influenced by search condition.

To further examine the influence of the salient feature difference - the orientation of the oblique - search slopes for the Chinese groups in the previous experiment and in the present experiment were analyzed together. An ANOVA, with target presence and search condition as within-subjects factors and experiment (Experiment 2 vs. 3) as a between-subjects factor, revealed that the overall search slopes did not differ between the two experiments $(F<1)$. As was expected, the presence of a search asymmetry between the $\mathrm{U}-\mathrm{F}$ and $\mathrm{F}-\mathrm{U}$ conditions was found, as is indicated by the main effect of search condition $[F(1,18)=62.36, p<.001]$. More important, the search in the U-F condition was more efficient with the presence of a salient feature difference (Experiment 3 ) than without [Experiment $2 ; F(1,18)=8.01, p<.05]$, resulting in a more pronounced search asymmetry in Experiment 3 than in Experiment $2[F(1,18)=5.90, p<.05]$. This finding was even more impressive, considering the fact that the familiar target in the present experiment was lower in terms of character frequency than that in Experiment 2 (44.2 per million for 舌 in Experiment 3 vs. 292.0 per million for 古 in Experiment 2). Taken together, the contrast between Experiments $1 \mathrm{~A}$ and $1 \mathrm{~B}$ and the contrast between Experiments 2 and 3 provide convergent evidence for the role of low-level feature differences in mediating a strong familiarity-based search asymmetry and an efficient pop-out-like search in the U-F condition.

\section{EXPERIMENT 4}

Having established that the strong search asymmetry and efficient visual search in the U-F search condition were due, at least in part, to the presence of the oblique feature differences between the familiar and the unfamiliar characters, we planned to further investigate the 

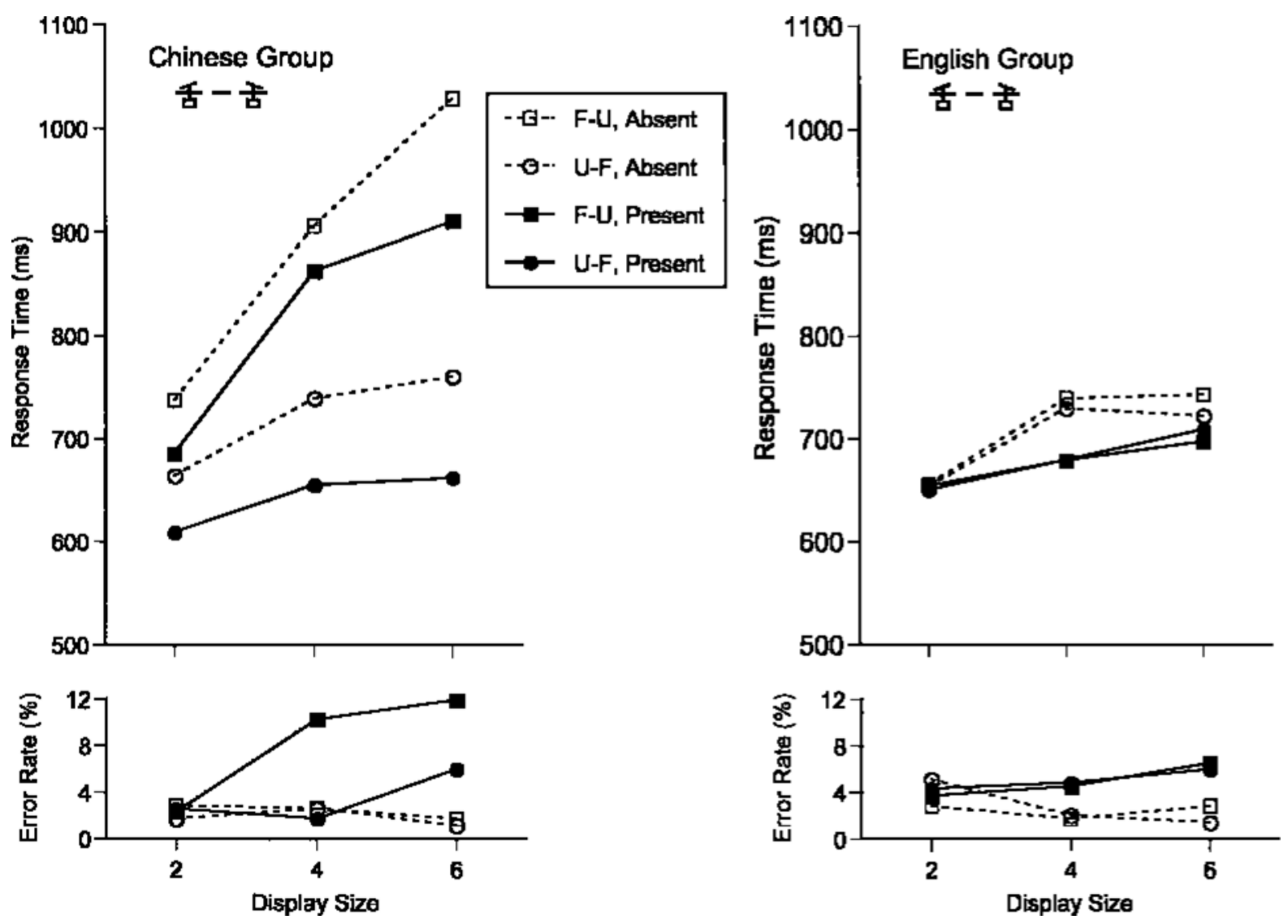

Figure 3. Response times and error rates as a function of target presence, search condition, and display size for the Chinese group and the English group in Experiment 3. F-U, familiar target among unfamiliar distractors; U-F, unfamiliar target among familiar distractors.

role of target and distractor familiarity in determining search efficiency. As was mentioned earlier, Wang et al. (1994) argued that a familiarity difference between the target and the distractors, rather than the familiarity of the distractors, leads to efficient search performance in the U-F condition. In the present study, we tried to investigate this issue while controlling the familiarity and physical attributes of the stimuli. We used two common Chinese characters, 古 (meaning old or ancient) and 叶 (meaning leaf), and their $180^{\circ}$ rotated forms, 支 and $\mathrm{t}$, which were unfamiliar to native Chinese readers. Both 古 and 叶 are familiar characters, with a character frequency of 292.0 and 206.9 per million, respectively (Beijing Institute of Language Teaching and Research, 1986). All these forms were composed of a rectangle and a plus sign and differed only in the relative positions of these components. As in Experiment 2, 古 (familiar) and 무 (unfamiliar) were used as search targets. In addition, 叶 (familiar) and to (unfamiliar) served as distractors. Accordingly, four different target-distractor pairs were formed as follows: F-F (searching for 古 among 叶s), F-U (searching for 古 among $t_{\mathrm{s}} \mathrm{s}$ ), U-F (searching for 무 among 叶s), and U-U (searching for 무 among ta $s$ ).
Note that in each condition, the distractor could be obtained by rotating the target $90^{\circ}$ clockwise or counterclockwise. Therefore, low-level features, target-distractor similarity (Duncan \& Humphreys, 1989), and emergent features (Pomerantz, 1981) were closely matched across search conditions, which differed in the pairing of target familiarity and distractor familiarity.

\section{Method}

Participants. Twenty-four native Chinese speakers and 24 native English speakers participated in a single 1-h session. They received $\$ 10$ or a course credit for their participation.

Design. For both the Chinese group and the English group, half of the participants took part in a blocked condition, and the other half in a mixed condition. In the blocked condition, both the target and the distractor familiarity were blocked. That is, the identities of the target and the distractor were specified at the beginning of each block and remained the same throughout the block. Eight blocks of 72 trials were used, representing two replicas of all combinations of target and distractor familiarity (F-F, F-U, U-F, and U-U conditions). The order of the search conditions was counterbalanced across participants. In the mixed condition, the target was blocked, whereas the distractor type was randomized. That is, the target identity was fixed within each block, whereas the distractors could be either familiar or unfamiliar in a given trial. Thus, in the mixed condition, 
both the F-F and the F-U searches could appear in the same block. Similarly, both the U-F and the U-U searches were presented in the same block. Eight blocks were used to represent four replicas of each target.

For both the blocked and the mixed conditions, a five-factor mixed design was used. Target presence (absent or present), target familiarity (familiar or unfamiliar), distractor familiarity (familiar or unfamiliar), and display size (2, 4, or 6) were the within-subjects factors, and group (Chinese vs. English) was the between-subjects factor.

\section{Results and Discussion}

Trials with incorrect responses (about $2.0 \%$ for both the Chinese group and the English group) were eliminated from further analysis. Extreme RTs that were more than 2.5 standard deviations above or below the mean (2.6\% for the Chinese group and 2.5\% for the English group) were also excluded. For each combination of target and distractor familiarity, search slopes for targetpresent and target-absent trials were produced separately by a linear regression of RT on display size. A preliminary analysis revealed that search performance did not differ between the blocked condition and the mixed condition (no significant main effect of this manipulation or its interaction with other factors). As a result, data are presented collapsed across these two conditions. Table 4 presents the search slopes and error rates, and Figure 4 shows RTs and error rates for both the Chinese group and the control group.

A repeated measures ANOVA was conducted on search slopes, with target presence, target familiarity, and distractor familiarity as within-subjects factors and group as a between-subjects factor. There was a main effect of distractor familiarity $[F(1,46)=10.22, p<.01]$, which was qualified by a significant interaction with group $[F(1,46)=18.54, p<.001]$. To better appreciate the differences in search efficiency between these two groups of participants, search slopes for each group were subjected to separate repeated measures ANOVAs, with target-presence, target familiarity, and distractor familiarity as within-subjects factors.

Figure 4 revealed that for the Chinese group, search was more efficient when the distractors were familiar

Table 4

Search Slopes (in Milliseconds/Item) and Error Rates (ERs, in \%) for Both the Chinese Group and the English Group in Experiment 4

\begin{tabular}{|c|c|c|c|c|c|c|c|}
\hline \multirow[b]{3}{*}{ Group } & \multirow{3}{*}{$\begin{array}{c}\text { Search } \\
\text { Condition } \\
\end{array}$} & \multicolumn{3}{|c|}{ Target Present } & \multicolumn{3}{|c|}{ Target Absent } \\
\hline & & \multicolumn{2}{|c|}{$\underline{\text { Search Slope }}$} & \multirow[b]{2}{*}{ ER } & \multicolumn{2}{|c|}{ Search Slope } & \multirow[b]{2}{*}{ ER } \\
\hline & & $M$ & $S E$ & & $M$ & $S E$ & \\
\hline \multirow[t]{4}{*}{ Chinese } & $\mathrm{F}-\mathrm{F}$ & 25.9 & 3.8 & 3.7 & 38.1 & 5.3 & 1.3 \\
\hline & $\mathrm{F}-\mathrm{U}$ & 42.0 & 4.9 & 2.3 & 51.3 & 8.8 & 0.9 \\
\hline & U-F & 28.7 & 3.6 & 2.9 & 33.4 & 6.3 & 0.9 \\
\hline & $\mathrm{U}-\mathrm{U}$ & 40.6 & 4.7 & 2.9 & 46.5 & 8.1 & 1.1 \\
\hline \multirow[t]{4}{*}{ English } & $\mathrm{F}-\mathrm{F}$ & 8.9 & 2.2 & 1.5 & 22.7 & 7.6 & 2.0 \\
\hline & $\mathrm{F}-\mathrm{U}$ & 6.2 & 3.2 & 2.1 & 13.0 & 4.1 & 1.9 \\
\hline & U-F & 4.0 & 2.1 & 2.6 & 18.8 & 5.3 & 1.9 \\
\hline & U-U & 5.8 & 2.4 & 2.1 & 21.5 & 5.4 & 1.9 \\
\hline
\end{tabular}

Note-F-F, familiar target among familiar distractors; F-U, familiar target among unfamiliar distractors; U-F, unfamiliar target among familiar distractors; $\mathrm{U}-\mathrm{U}$, unfamiliar target among unfamiliar distractors.
(31.5 msec/item) than when they were unfamiliar $(44.8 \mathrm{msec} /$ item $)[F(1,23)=19.18, p<.001]$. As in Experiment 2 , the present experiment demonstrated that the U-F search was more efficient than the F-U search. However, target familiarity seemed to be relatively unimportant. Neither the main effect of target familiarity nor its interaction with other factors was significant (all $F \mathrm{~s}<$ $2.10, p \mathrm{~s}>.05)$. Thus, the manipulation of target familiarity (古 vs. 古) did not influence search efficiency, despite the fact that the same stimulus contrast was effective in producing the asymmetry effect reported in Experiment 2 . Taken together, the findings from both the present experiment and Experiment 2 support the conclusion that distractor familiarity is largely responsible for the finding of the $\mathrm{U}-\mathrm{F}$ versus $\mathrm{F}-\mathrm{U}$ search asymmetry.

For the English group, as was expected, there was no main effect of target familiarity or distractor familiarity and no interaction between them (all $F$ s $<1$ ). The only significant effect was the main effect of target presence $[F(1,23)=8.74, p<.01]$, indicating that search slopes were steeper in the target-absent trials than in the targetpresent trials. Similar to Experiments 2 and 3, the overall search slopes were much shallower for the English group (12.6 msec/item) than for the Chinese group [38.2 msec/ item; $F(1,46)=22.66, p<.001]$. For the English group, all slopes in the target-present trials were approximately $8 \mathrm{msec} / \mathrm{item}$, which qualified as pop-out searches according to Wang et al. (1994).

The overall error rate was about $2.0 \%$ for both the Chinese group and the English group $(F<1)$. There were no significant main effects of target familiarity or distractor familiarity and no interaction between these two factors (all $\left.F_{\mathrm{S}}<1\right)$.

\section{GENERAL DISCUSSION}

In the present study, the influence of stimulus familiarity and low-level feature difference on visual search asymmetry was examined. In all four experiments, we found that searching for an unfamiliar target among familiar distractors (U-F) is more efficient than searching for a familiar target among unfamiliar distractors (F-U), replicating the familiarity-based search asymmetry reported in previous studies (Frith, 1974; Reicher et al., 1976; Richards \& Reicher, 1978; Wang et al., 1994). We further demonstrated that feature difference contributes to the size of the asymmetry effect and, in the absence of other salient cues, may determine whether or not an efficient pop-out-like search occurs in the U-F search condition. The results of Experiment 4 indicate that the U-F versus $\mathrm{F}-\mathrm{U}$ search asymmetry is mainly attributable to differences in distractor familiarity.

Our conclusions are at odds with the arguments advanced by Wang et al. (1994). In their study, they demonstrated a pop-out effect in the U-F condition and an inefficient search in the F-F condition. On the basis of this finding, they argued for the importance of a familiarity difference between the search target and the distractors in producing efficient search performance. However, in 

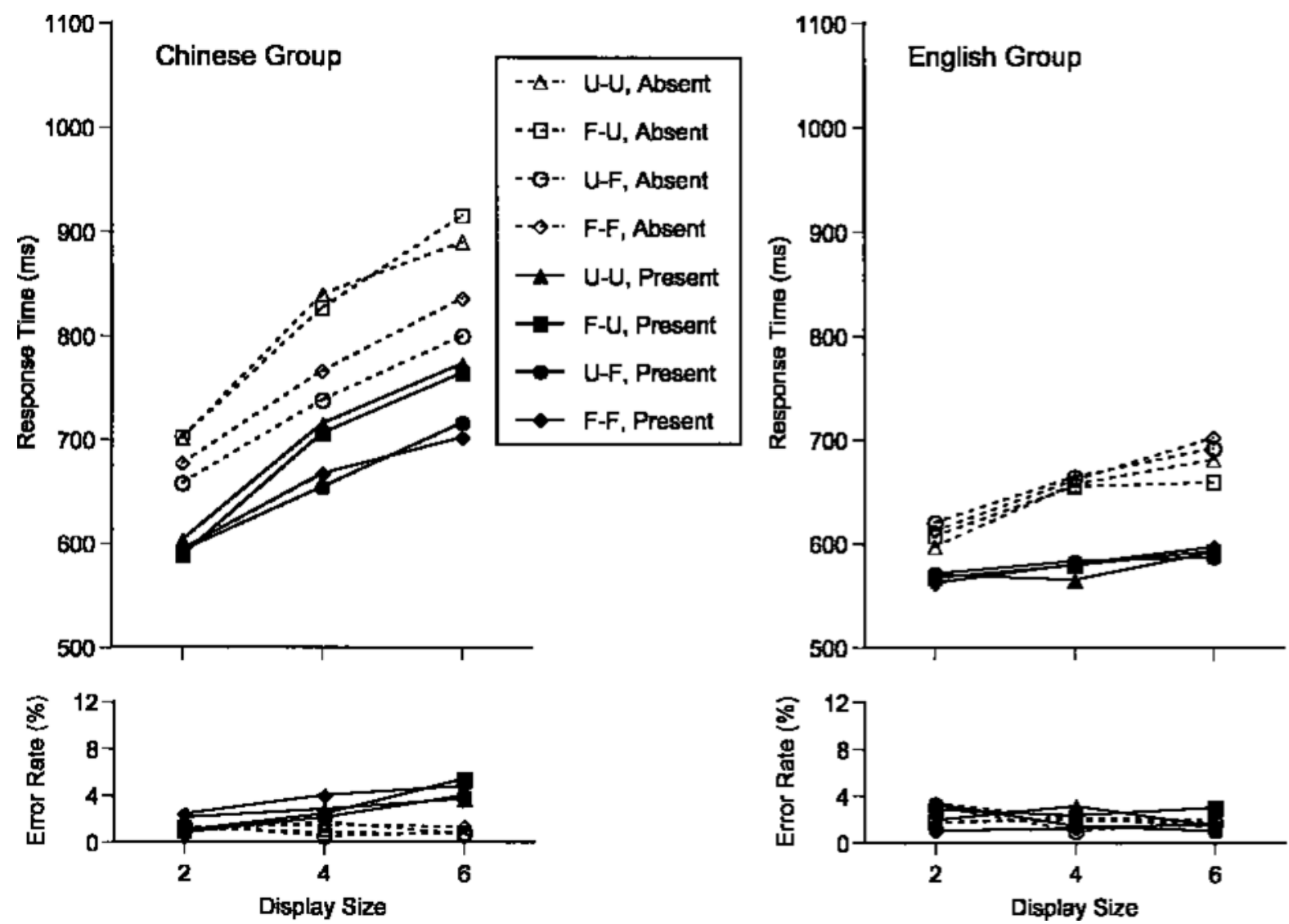

Figure 4. Response times and error rates as a function of target presence, target familiarity, distractor familiarity, and display size for the Chinese group and the English group in Experiment 4. U-U, unfamiliar target among unfamiliar distractors; F-U, familiar target among unfamiliar distractors; U-F, unfamiliar target among familiar distractors; F-F, familiar target among familiar distractors.

the present study, we found that for both the familiar and the unfamiliar targets, search is more efficient among familiar distractors than among unfamiliar distractors; neither the target familiarity nor the interaction between target familiarity and distractor familiarity influences search efficiency. Thus, the present investigation suggests that the search asymmetry between the $\mathrm{U}-\mathrm{F}$ and the $\mathrm{F}-\mathrm{U}$ conditions is mainly an effect of distractor familiarity. Several previous studies have suggested that unfamiliar stimuli, such as rotated or mirror-reversed letters, are more difficult to process in general (e.g., Greenberg \& Krueger, 1983; Krueger, 1975, 1984). In searching for a target among unfamiliar distractors, participants have to wade through the display items, owing to their lack of experience with and weak representation of those stimuli. In contrast, familiar stimuli may be activated and processed faster (Regan, 1981). When searching through a familiar background, participants could identify and rule out the distractors more efficiently. Thus, the $\mathrm{U}-\mathrm{F}$ versus $\mathrm{F}-\mathrm{U}$ search asymmetry may result from the fact that distractors outnumber the search target in a display and, thus, the familiarity status of the distractors was more influential (Krueger, 1984; Reicher et al., 1976; Richards \&
Reicher, 1978; Treisman \& Souther, 1985). Another possibility is that distractor familiarity facilitates the grouping of background items and thus leads to better target detection (Karni \& Sagi, 1991; Treisman, 1982).

A recent study by Malinowski and Hübner (2001) also attempted to examine the mechanisms underlying the familiarity-based search asymmetry. They had both German and Slavic participants search for $\mathrm{N}$ among $h \mathrm{~s}$ or $\Lambda$ among Ns. Since the German participants were familiar with $N$ only, whereas their Slavic counterparts were familiar with both $\mathrm{N}$ and $\boldsymbol{h}$, this design provided an excellent test of the role of target familiarity on search performance by allowing comparisons of the U-F condition (the German group) with the F-F condition (the Slavic group) using exactly the same stimuli ( $\Lambda$ among $\mathrm{Ns}$ ). In marked contrast to Wang et al. (1994), who reported a very inefficient $\mathrm{F}-\mathrm{F}$ search and a pop-out $\mathrm{U}-\mathrm{F}$ search, Malinowski and Hübner demonstrated a pop-out effect in both the F-F condition (the Slavic group) and the U-F condition (the German group). Thus, this finding provides convergent evidence that search asymmetry is largely determined by the familiarity of the distractors, rather than by the novelty of the target or the familiarity 
difference between the target and the distractors. As was mentioned earlier, in Wang et al., a salient feature difference, the orientation of the oblique, was found in the U-F condition ( $\Lambda$ among $N$ s or $\Sigma$ among $Z s$ ), but not in the F-F condition ( $\Xi$ among 己s or $己$ among $\Xi$ s). Thus, the comparisons between different target-distractor pairs confounded stimulus familiarity with variation in lowlevel feature difference. The present study and the results reported by Malinowski and Hübner strongly suggest that this confound may have led to the finding of the more efficient U-F than F-F search reported by Wang et al.

The present study highlights the importance of controlling low-level feature differences in studying higher level familiarity effects. A similar point has been made regarding the alphanumerical category effect. When searching for a letter or a digit among a background of letters or digits, several early studies (e.g., Brand, 1971; Ingling, 1972; Jonides \& Gleitman, 1972) reported a more efficient between-categories search (a letter among digits or a digit among letters), as compared with a withincategory search (a letter among letters or a digit among digits). However, in later studies, with better control of physical differences across the within-categories versus the between-categories conditions, the category effect was diminished, eliminated, or even reversed (Cardosi, 1986; Krueger, 1984).

The present study has demonstrated that the presence of a salient low-level feature difference facilitates the search in the U-F condition and amplifies the magnitude of the familiarity-based search asymmetry. However, the underlying mechanisms for this interaction of stimulus familiarity and low-level features are still unclear. One possible explanation for this finding can be related to the effect of stimulus familiarity on the perception of constituent features. For example, Reingold and Jolicœur (1993) reported that a specific feature segment was identified better in the context of familiar letters, as compared with the unfamiliar symbols. Further studies would be required to determine whether such visual context effects are related to the present phenomenon.

Finally, a counterintuitive finding in the present study is that, despite the fact that Chinese characters and their transforms were used as search stimuli in Experiments 2, 3 , and 4, the search performance of the English control groups were far superior to that of their Chinese counterparts. In all these experiments, there was a comparable slowing of search for the Chinese group (about $24 \mathrm{msec} /$ item), as compared with the English control groups. Thus, familiarity with the search stimuli was actually detrimental to search performance. It is possible that the participants in the Chinese and English groups might have adopted qualitatively different search strategies. The Chinese participants might have viewed the stimuli more holistically, as familiar characters and their rotations or reflections. In contrast, the non-Chinese participants might have relied more on certain features or cues (e.g., the relative position of the plus or the rectangle in Experiment 2, the orientation of the oblique in Experiment 3, and the vertical vs. horizontal symmetry or elongation in Experiment 4). It is possible that for the Chinese group, the holistic character processing is obligatory and automatic, rather than a deliberate or controlled strategy. Consequently, their familiarity with the symbols may have prevented them from capitalizing on certain cues, thereby reducing search efficiency.

\section{REFERENCES}

Beck, J., \& AMBler, B. (1972). Discriminability of differences in line slope and in line arrangement as a function of mask delay. Perception \& Psychophysics, 12, 33-38.

Beijing Institute of Language Teaching and Research (1986). Hsien tai han yu $p$ `in lu $t z$ `u tien [A frequency dictionary of modern Chinese]. Beijing: Beijing Language Institute Press.

BRAND, J. (1971). Classification without identification in visual search. Quarterly Journal of Experimental Psychology, 23, 178-186.

CARDOSI, K. M. (1986). Some determining factors of the alphanumeric category effect. Perception \& Psychophysics, 40, 317-330.

Cheal, M., Lyon, D. R., \& Hubbard, D. C. (1991). Does attention have different effects on line orientation and line arrangement discrimination? Quarterly Journal of Experimental Psychology, 43A, 824-857.

Christie, J., \& KLEIN, R. M. (1996). Assessing the evidence for novel popout. Journal of Experimental Psychology: General, 125, 201-207.

Desimone, R, \& Duncan, J. (1995). Neural mechanisms of selective visual attention. Annual Review of Neuroscience, 18, 193-222.

Duncan, J., \& Humphreys, G. W. (1989). Visual search and stimulus similarity. Psychological Review, 96, 433-458.

Ellison, A., \& WALSH, V. (1998). Perceptual learning in visual search: Some evidence of specif icities. Vision Research, 38, 333-345.

EnNs, J. T., \& Rensink, R. A. (1991). Preattentive recovery of threedimensional orientation from line drawings. Psychological Review, 98, 335-351.

FrITH, U. (1974). A curious effect with reversed letters explained by a theory of schema. Perception \& Psychophysics, 16, 113-116.

Goldstone, R. L. (1998). Perceptual learning. Annual Review of Psychology, 49, 585-612.

Greenberg, S. N., \& Krueger, L. E. (1983). Effect of letter orientation and sequential redundancy on the speed of letter search. Memory \& Cognition, 11, 181-191.

INGLING, N. W. (1972). Categorization: A mechanism for rapid information processing. Journal of Experimental Psychology, 94, 239-243.

Johnston, W. A., \& Schwarting, I. S. (1996). Reassessing the evidence for novel popout. Journal of Experimental Psychology: General, 125, 208-212.

Jonides, J., \& Gleitman, H. (1972). A conceptual category effect in visual search: $\mathrm{O}$ as letter or as digit. Perception \& Psychophysics, 12, 457-460.

KARNI, A., \& SAGI, D. (1991). Where practice makes perfect in texture discrimination: Evidence for primary visual cortex plasticity. Proceedings of the National Academy of Sciences, 88, 4966-4970.

Krueger, L. E. (1975). Familiarity effects in visual information processing. Psychological Bulletin, 82, 949-974.

KRUEGER, L. E. (1984). The category effect in visual search depends on physical rather than conceptual differences. Perception \& Psychophysics, 35, 558-564.

KueHN, S. M., \& Joliceur, P. (1994). Impact of quality of the image, orientation, and similarity of the stimuli on visual search for faces. Perception, 23, 95-122.

Lajoy, R. J., \& SeEthoff, P. M. (1974). Effects of familiarity, verbal response, and practice on a visual search task. Perceptual \& Motor Skills, 38, 1311-1314.

Malinowski, P., \& HÜBner, R. (2001). The effect of familiarity on visual-search performance: Evidence for learned basic features. Perception \& Psychophysics, 63, 458-463.

Polk, T. A., \& FARAH, M. J. (1995). Late experience alters vision. $\mathrm{Na}$ ture, 376, 648-649.

Pomerantz, J. R. (1981). Perceptual organization in information pro- 
cessing. In M. Kubovy \& J. Pomerantz (Eds.), Perceptual organization (pp.141-180). Hillsdale, N.J: Erlbaum.

REgan, J. E. (1981). Effect of familiarity on multielement matching. Journal of Experimental Psychology: Human Perception \& Performance, 7, 1273-1282.

Reicher, G. M., SNyder, C. R. R., \& Richards, J. T. (1976). Familiarity of background characters in visual scanning. Journal of Experimental Psychology: Human Perception \& Performance, 2, 522-530.

Reingold, E. M., \& Jolicceur, P. (1993). Perceptual versus postperceptual mediation of visual context effects: Evidence from the lettersuperiority effects. Perception \& Psychophysics, 53, 166-178.

Richards, J. T., \& ReIcher, G. M. (1978). The effect of background familiarity in visual search: An analysis of underlying factors. Perception \& Psychophysics, 23, 499-505.

Schneider, W., \& Shiffrin, R. M. (1977). Controlled and automatic human information processing: I. Detection, search and attention. Psychological Review, 84, 1-66.

Shiffrin, R. M., \& SchneIder, W. (1977). Controlled and automatic human information processing: II. Perceptual learning, automatic attending and a general theory. Psychological Review, 84, 127-190.

Singer, M. H., \& LAPPIN, J. S. (1976). Similarity: Its definition and effect on the visual analysis of complex displays. Perception \& Psychophysics, 19, 405-411.

Sun, J. Y., \& Perona, P. (1996). Preattentive perception of elementary three-dimensional shapes. Vision Research, 36, 2515-2529.

SuzuKi, S., \& CAVANAGH, P. (1995). Facial organization blocks access to low-level features: An object inferiority effect. Journal of Experimental Psychology: Human Perception \& Performance, 21, 901-913.
Treisman, A. (1982). Perceptual grouping and attention in visual search for features and for objects. Journal of Experimental Psychology: Human Perception \& Performance, 8, 194-214.

Treisman, A., \& Gormican, S. (1988). Feature analysis in early vision: Evidence from search asymmetries. Psychological Review, 95, 15-48.

Treisman, A., \& Souther, J. (1985). Search asymmetry: A diagnostic for preattentive processing of separable features. Journal of Experimental Psychology: General, 114, 285-310.

von GRÜnaU, M., \& DubÉ, S. (1994). Visual search asymmetry for viewing direction. Perception \& Psychophysics, 56, 211-220.

Wang, Q., Cavanagh, P., \& Green, M. (1994). Familiarity and pop-out in visual search. Perception \& Psychophysics, 56, 495-500.

Wolfe, J. M. (1998). Visual search. In H. Pashler (Ed.), Attention (pp. 1373). London: Psychology Press.

Wolfe, J. M., \& BennetT, S. C. (1997). Preattentive object files: Shapeless bundles of basic features. Vision Research, 37, 25-43.

\section{NOTES}

1. We reanalyzed all the experiments, using RT as the dependent measure and including display size as an independent measure. By and large, we found similar patterns of results, with RT $\times$ display size interactions mirroring the slope effects. For simplicity of exposition and conciseness, we reported the analyses of search slopes throughout the article.

(Manuscript received February 29, 2000; revision accepted for publication August 8, 2000.) 